\title{
PENGARUH MODEL PEMBELAJARAN LEARNING CONTRACT TERHADAP HASIL BELAJAR TEKNIK PENGELASAN SISWA SMK NEGERI 1 KAKAS
}

\author{
Abd Rizal Suluta ${ }^{1}$, Hendro M. Sumual ${ }^{2}$, J. D. I. Manongko ${ }^{3}$. Denny Maukar ${ }^{4}$ \\ Pendidikan Teknik Mesin FATEK Univeritas Negeri Manado \\ abdrizalsuluta106@gmail.com, hendrosumual@unima.ac.id,jenlymanongko@unima.ac.id \\ dennymaukar@unima.ac.id
}

\begin{abstract}
ABSTRAK
Tujuan utama pada penelitian ini adalah untuk mengetahui seberapa jauh peningkatan pembelajaran Learning Contract dengan hasil belajar teknik pengelasan peserta didik yang ada di SMK Negeri 1 Kakas. Pada kesempatan ini peneliti menggunakan pendekatan kuasi eksperiment dengan nonrandomized control-group pretest-posttest design. Untuk menguji perbedaan hipotesis dengan uji t-test untuk data yang berdistribusi normal, Peneliti menggunakan seluruh siswa kelas X Jurusan TKR SMK Negeri 1 Kakas yang berjumlah 26 siswa untuk populasi, sedangkan untuk sampel peneliti membagi dalam dua kelompok yakni kelompok eksperimen 13 siswa dan untuk kelompok kontrol 13 siswa. Berdasarkan hasil penelitian yang dilakukan bahwa terdapat perbandingan antara nilai $t_{\text {hitung }}$ dan $t_{\text {tabel }}$, dengan perolehan $t_{\text {hitung }}=4,156$ dan $t_{\text {tabel }}=2,064$. Untuk itu nilai $t_{\text {hitung }}$ lebih banyak nilainya pada $t_{\text {tabel. }}$. Jadi, dikatakan bahwa Ho tidak berpengaruh sedangkan Ha berpengaruh. Maka dari itu pembelajaran learning contract mampu meningkatkan teknik pengelasan siswa SMK Negeri 1 Kakas khususnya kelas X.
\end{abstract}

Kata Kunci: Model Pembelajaran, Learning Contract, Hasil Belajar.

\section{ABSTRACT}

Tha main objective of this research is to find out how far the learning contract learning has improved with the learning outcomes of the students at SMK Negeri 1 Kakas. On this occasion, the researcher used a quasi-eksperimental approach with a nonrandomized control-group pretest-posttest design. To test the difference between the hypotheses using the t-test for normally distributed data, the researcher used all class $X$ students of the TKR department of SMK Negeri 1 Kakas, totaling 26 students for the population, while for the sample the researchers divided into two groups, namely the eksperimental group of 13 students and for the control group of 13 students. Based on the results of research conducted that there is a comparison between the value of t and table, with the acquisition of the count=4,156 and the table $=2,064$. For this reason, the value of t count has more value on the table. Thus, it is said that ho has no effect while ha does. Therefore, learning contract learning is able to improve the welding technique of students of SMK Negeri 1 Kakas, especially class X.

Keywords: Learning Model, Learning Contract, Learning Outcomes. 


\section{PENDAHULUAN}

Model pembelajaran disebut juga suatu cara yang dapat digunakan baik dalam penyajian materi maupun menyampaikan materi dalam pembelajaran. Dalam proses pembelajaran guru harus bisa memilih metode yang akan digunakan agar siswa tertarik dan menyenangkan dalam proses pembelajaran agar bisa mempengaruhi hasil belajar siswa dalam pelajaran tersebut.

Proses belajar mengajar pada teknik pengelasan terutama pada kelas $\mathrm{X}$ belum bersifat aktif, dimana siswa hanya sebagai penerima saja. Tanpa adanya kegiatan-kegiatan lain untuk menimbulkan keaktifan belajar yang diinginkan oleh siswa. Sehingga semangat anak dalam belajar semakin menurun. Dan anak akan dengan cepat merasa bosan dalam mengikuti pembelajaran.

Dari hasil observasi yang peneliti lakukan pada SMK Negeri 1 Kakas khususnya kelas $\mathrm{X}$ banyak siswa yang tidak bersemangat saat pembelajaran berlangsung, mengantuk saat pembelajaran berlangsung, tidak betah dalam mengikuti pembelajaran, sering berbincangbincang dengan teman-teman saat pembelajaran berlangsung, serta kurang memperhatikan materi yang disampaikan saat proses mengajar. Disamping itu, kemandirian siswa dalam menguasi materi pelajarpun masih rendah, bahkan siswa ataupun pendidik tidak akan mengetahui keterampilan yang dimiliki peserta didik karena kegiatan belajar hanya dilakukan dengan sesimpel saja yaitu pendidik menjelaskan materi kemudian siswa memperhatikan penjelasan serta menulis kembali apa yang dijelaskan.

Hal ini dapat dinilai ketika pendidik menyampaikan suatu materi atau meriview kembali materi banyak siswa yang tidak mampu untuk menjawab. Proses pembelajaranpun yang relatif masih sederhana ini meyebabkan hasil belajar siswa dalam pembelajaran masih dianggap kurang relatif. Dengan adanya model pembelajaran learning contract dapat membuat siswa lebih aktif dan relatif yang akan menjadikan siswa lebih mandiri serta paham pada mata pelajaran yang akan dipelajari dikelas, yang dapat membuat hasil belajar menjadi lebih baik.

Berdasarkan permasalahan yang ada maka peneliti bertujuan untuk meneliti dengan judul "Pengaruh Model Pembelajaran Learning Contarct Terhadap Hasil Belajar Teknik Pengelasan Siswa SMK Negeri 1 Kakas".

\section{KAJIAN PUSTAKA}

Kontrak belajar merupakan kesepakatan antara guru dan siswa dalam proses pembelajaran, sehingga siswa dan guru mampu saling bertukar pikiran dalam proses pembelajaran yang berlangsung. Agar dapat menghasilkan hasil belajar yang baik.

Learning Contract bukanlah peraturan yang dibuat berdasarkan paksaan melainkan kesepakatan. Adanya kontrak belajar di kelas, akan menegaskan batasan antara hak dan kewajiban siswa, selain itu siswa dan guru akan terlatih untuk berhati-hati sebelum melakukan tindakan.

Model Pembelajaran ini dianggap sebagai cara yang paling efektif untuk membuat kesepakatan antara lain: (a) semua siswa dapat mengerjakan tugas sekolah (b) Rencana pembelajaran dapat terlaksana dengan baik; (c) Menjadi terlatih untuk melakukan evaluasi pribadi; (d) Dapat mempermudah guru menyampaikan materi pembelajaran; dan (e) peserta didik menjadi aktif dalam sebuah pembelajaran.

Adapun kelebihan dari learning contarct adalah sebagai berikut:

a. Meningkatkan karakteristik, sikap, perilaku dan hasil belajar siswa.

b. Memudahkan guru dalam melaksanakan tugas yang di rangkum dalam RPP.

c. Aktifitas belajar untuk efektif (Hisyam Zaini, dkk, 2008 )

d. Memberikan cara belajar baru bagi siswa(http://journal. Student.uny.ac.id) 
Adapun kekurangan model pembelajran learning contract sebagai berikut: Membutuhkan waktu yang lama, Tidak Cocok untuk peserta didik yang memiliki kepribadian yang tidak jelas dan memiliki pola belajar yang terstruktur. Maksudnya selalu bergantungan dengan guru serta tidak mau mandiri.

Prosedur dalam menerapkan learning contract ini adalah:

a. Siswa dipersilahkan memilih topik dalam pembelajaran, tetapi topik tersebut tidak keluar dari materi yang sedang diajarkan.

b. guru akan membimbing siswa dalam membuat rencana studi secara teratur dan terukur.

c. kemudian guru meminta siswa membuat komtrak belajar secara tertulis mencakup kategori sebagai berikut:

- Topik yang dipelajari.

- Pengetahuan atau kemampuan spesifik yang akan dicapai peserta didik.

- Kegiatan belajar yang akan dikerjakan.

- Waktu.

- Bukti yang akan dihadirkan siswa untuk menunjukkan bahwa tujuan-tujuan itu telah dicapai.

Dalam pembuatan kontrak belajar, siswa harus memahami isi kontrak dan menandatangani tanpa adanya paksaan dan secara sukarela melaksanakannya. Dan guru akan memberikan masukan mengenai pembelajaran serta langkah-langkah yang diperlukan.

Langkah-langkah Learning contract yang harus disepakati bersama antara lain:

\begin{tabular}{|c|l|}
\hline Topik & \multicolumn{2}{|c|}{ Catatan Resume } \\
\hline $\mathbf{1}$ & \multicolumn{2}{|c|}{$\mathbf{2}$} \\
\hline Tujuan Belajar & $\begin{array}{l}\text { Mempresentasikan saya } \\
\text { sendiri dalam suasana } \\
\text { meneyenangkan diatas } \\
\text { kertas }\end{array}$ \\
\hline
\end{tabular}

\begin{tabular}{|c|c|}
\hline $\begin{array}{l}\text { Pengetahuan } \\
\text { Khusus }\end{array}$ & $\begin{array}{l}\text { Memilih format yang } \\
\text { sesuai: } \\
\text { - } \\
\text { Menyingkat } \\
\text { empat halaman } \\
\text { menjadi dua } \\
\text { halaman. } \\
\text { - } \text { Menulis tujuan } \\
\text { pembelajaran } \\
\text { yang jelas. }\end{array}$ \\
\hline $\begin{array}{l}\text { Aktivitas } \\
\text { Belajar }\end{array}$ & $\begin{array}{l}\text { Mengulangi Contoh } \\
\text { Resume. } \\
\text { - Memilih learning } \\
\text { contract sebagai } \\
\text { metode } \\
\text { pembelajaran. } \\
\text { - Meriview } \\
\text { kembali materi } \\
\text { belajar. } \\
\text { Mengirim tugas yang } \\
\text { diberikan ke tiga orang } \\
\text { atau lebih dan perintahkan } \\
\text { mereka untuk memeriksa } \\
\text { dan memberikan } \\
\text { komentar. }\end{array}$ \\
\hline Waktu & 2 Minggu \\
\hline
\end{tabular}

Menurut para ahli hasil belajar adalah kemampuan-kemampuan yang dimiliki siswa setelah menerima pengalaman belajarnya (Sudjana, 2004). Sedangkan menurut Horwart Kingsley dalam bukunya Sudjana membagi tiga macam hasil belajar mengajar: (a) Keterampilan dan kebiasaan; (b) Pengetahuan dan pengarahan; dan (c) Sikap dan cita-cita.

Untuk mengetahui hasilnya nanti bisa dilihat dari tugas yang diberikan serta penilaian yang akan guru lakukan dalam proses pembelajaran atau dalam masa kontrak berlangsung. Dan adapun faktor yang bisa mempengaruhi hasil belajar antara lain dari siswa itu sendiri serta dari pergaulan dan juga 
lingkungan. Hal ini sangat mempengaruhi hasil belajar siswa.

Pada pembelajaran yang menggunakan model pembelajaran learning contract dijadikan salah satu strategi yang dapat meningkatkan hasil belajar siswa. Dengan adanya penggunaan model pembelajaran learning contract dalam kegiatan proses belajar mengajar dapat menyebabkan hasil belajar siswa pada saat evaluasi menjadi meningkat.

Tujuannya yaitu apakah terdapat peningkatan dalam pembelajaran pengelasan dengan menggunakan learning contract atau tidak terdapat peningkatan pada pengelasan.

\section{METODE PENELITIAN}

Sesuai dengan tujuan maka peneliti menggunakan kualitatif dengan bentuk eksperimen, dimana dalam proses pembelajaran apakah terdapat pengaruh dengan memberikan perlakuan tertentu dengan perlakuan yang lain dengan terkontrol dan terkendali.

Pada penelitian eksperimen ini peneliti membagi dua kelompok antara kelompok eksperimen dan kelompok kontrol.

Grup siklus I treatment siklus II

\begin{tabular}{|cccc|}
\hline Eksamen & X1 & T1 & X2 \\
Kontrol & Y1 & & Y2 \\
\hline
\end{tabular}

Peneliti mengikuti prosedur sebagai berikut:

1. Pada langkah pertama dilakukan pretest yaitu dengan menggunakan soal objektif. Dengan bertujuan untuk mengetahui keadaan awal untuk masing-masing kelas.

2. Langkah yang kedua yaitu treatment atau perlakuan yang dilakukan terhadap kedua kelas. Dimana perlakuan terhadap kelas kontrol memakai metode ceramah sedangkan kelas eksperimen diberikan perlakuan menggunakan model learning contract. Namun langkah ini dapat dilakukan setelah memenuhi syarat dari langkah yang pertama.

3. Langkah yang terakhir yaitu posttest dilakukan dengan memberikan soal objektif pada langkah pertama untuk mengetahui apakah terdapat pengaruh atau tidak terhadap kedua kelas tersebut.

Eksperimen merupakan rancangan yang digunakan pada penelitian ini dengan menggunakan kontrol dan eksperimen.

\section{PEMBAHASAN}

Interprestasi Data Kelompok Eksperimen $\left(\mathrm{X}_{1}\right)$ yang diajar dengan Learning Contract

Data variabel kelompok eksperimen yang diajar dengan learning contract terbukti bahwa nilai yang paling tinggi adalah 95 dan nilai yang paling rendah adalah 75 . Berdasarkan nilai tersebut diperoleh nilai modus sebesar 85 , nilai median 85 , maka nilai rata-rata sebesar 86,15 dan simpangan baku 5,83.

Tabel 4.1 Tabel Data Hasil belajar siswa teknik pengelasan dengan menggunakan Kelompok Eksperiment yang diajar dengan Model pembelajaran Learning Contract

\begin{tabular}{|c|c|c|c|c|}
\hline $\begin{array}{c}\text { Nila } \\
\text { i }\end{array}$ & $\begin{array}{l}\text { Rent } \\
\text { ang } \\
\text { nilai }\end{array}$ & $\begin{array}{l}\text { Class } \\
\text { limits }\end{array}$ & $\begin{array}{c}\text { Frekue } \\
\text { nsi } \\
\text { siswa }\end{array}$ & $\begin{array}{c}\text { Frekuen } \\
\text { si } \\
\text { Persen }\end{array}$ \\
\hline 1 & $\begin{array}{c}75- \\
79\end{array}$ & 74.5 & 1 & 7,69 \\
\hline 2 & $\begin{array}{c}80- \\
84\end{array}$ & 79.5 & 2 & 15,38 \\
\hline 3 & $\begin{array}{c}85- \\
89\end{array}$ & 84.5 & 5 & 38,46 \\
\hline 4 & $\begin{array}{c}90- \\
94\end{array}$ & 89.5 & 3 & 23,08 \\
\hline 5 & $\begin{array}{c}95- \\
99\end{array}$ & 94.5 & 2 & 15,39 \\
\hline \multicolumn{3}{|c|}{ Jumlah } & 13 & $100 \%$ \\
\hline
\end{tabular}


Berdasarkan tabel 4.1 diketahui nilai pretest kelompok eksperimen dengan menggunakan pembelajaran learning contract untuk nilai tertinggi adalah $38,47 \%$ (nilai 90 99); dan nilai terendah adalah 7,69\% (nilai 79 79). Data tersebut dapat disajikan hiterogen berikut ini.

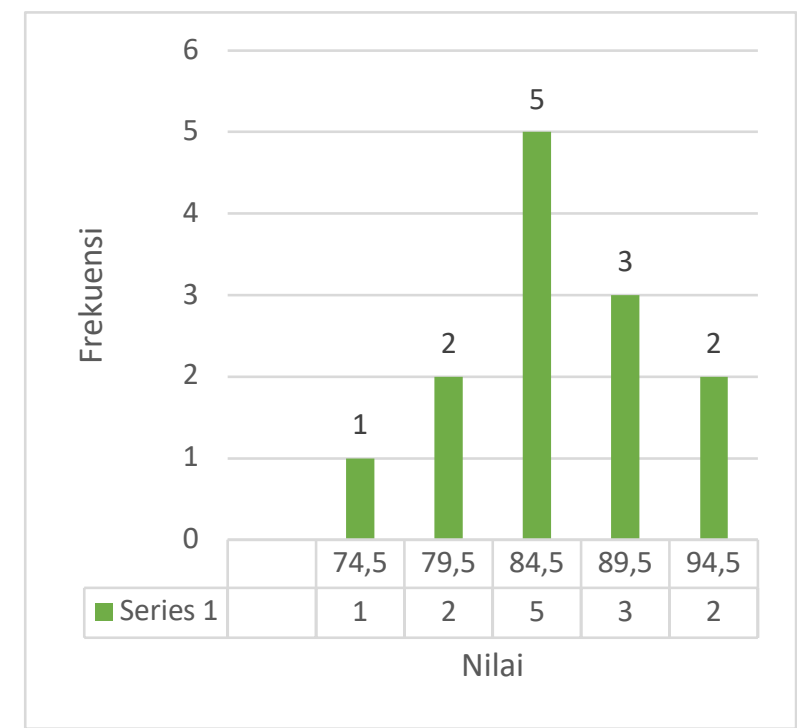

Gambar 4.1. Histogram Data Hasil Belajar Teknik Pengelasan Kelompok Eksperimen yang diajar dengan Model Pembelajaran Learning Contract

Tabel 4.2 Nilai Frekuensi Teknik Pengelasan Kelompok Kontrol yang tidak diajar dengan Learning Contract

\begin{tabular}{|c|c|c|c|c|}
\hline $\begin{array}{c}\text { Kela } \\
\text { s }\end{array}$ & $\begin{array}{c}\text { Renta } \\
\text { ng } \\
\text { nilai }\end{array}$ & $\begin{array}{l}\text { Class } \\
\text { limits }\end{array}$ & $\begin{array}{c}\text { Frekue } \\
\text { nsi } \\
\text { siswa }\end{array}$ & $\begin{array}{c}\text { Frekue } \\
\text { nsi } \\
\text { Persen }\end{array}$ \\
\hline 1 & $\begin{array}{c}70- \\
74\end{array}$ & 69.5 & 2 & 15,38 \\
\hline 2 & $\begin{array}{c}75- \\
79\end{array}$ & 74.5 & 3 & 23,08 \\
\hline 3 & $\begin{array}{c}80- \\
84\end{array}$ & 79.5 & 5 & 38,46 \\
\hline 4 & $\begin{array}{c}85- \\
89\end{array}$ & 84.5 & 2 & 15,39 \\
\hline 5 & $\begin{array}{c}90- \\
94\end{array}$ & 89.5 & 1 & 7,69 \\
\hline \multicolumn{3}{|c|}{ Jumlah } & 13 & $100 \%$ \\
\hline
\end{tabular}

Diketahui nilai pre-test kelompok kontrol dengan tidak menggunakan pembelajaran learning contract untuk nilai tertinggi adalah $23,08 \%$ (nilai 85 - 94); menengah $61,54 \%$ (nilai 75 - 84); dan terendah $15,38 \%$ (nilai $70-74$ ).

\section{Pengujian Persyaratan Analisis Uji Normalitas Data}

Uji normalitas menggunakan bantuan excel dengan rumus lilliefors. Untuk mengetahui apakah berdistribusi normal atau tidak. Kriteria yang digunakan yaitu diperoleh data yang berdistribusi normal apabila nilai siknifikasi > dari 0,05 .

Tabel 4.3 Pre-Test Hasil belajar teknik pengelasan Kelompok Eksperimen dan Kelompok Kontrol.

\begin{tabular}{|c|c|c|c|c|}
\hline \multicolumn{3}{|c|}{ Penghitungan } \\
$\begin{array}{c}\text { Varia } \\
\text { bel }\end{array}$ & $\begin{array}{c}\text { Taraf } \\
\text { nyata } \alpha\end{array}$ & $\mathbf{L}_{\text {hitung }}$ & $\mathbf{L}_{\text {tabel }}$ & Ket \\
\hline $\begin{array}{c}\text { Kelo } \\
\text { mpok } \\
\text { ekspe } \\
\text { rimen } \\
\left(\mathrm{X}_{1}\right)\end{array}$ & \multirow{2}{*}{0,05} & 0,1947 & 0,234 & $\begin{array}{c}\text { Berdis } \\
\text { tribusi } \\
\text { Norm } \\
\text { al }\end{array}$ \\
\cline { 1 - 4 } $\begin{array}{c}\text { Kelo } \\
\text { mpok } \\
\text { kontr } \\
\text { ol } \\
\left(\mathrm{X}_{2}\right)\end{array}$ & & 0,1899 & 0,234 & $\begin{array}{c}\text { Berdis } \\
\text { tribusi } \\
\text { Norm } \\
\text { al }\end{array}$ \\
\cline { 3 - 5 } & & $\mathbf{L}_{\text {hitung }}<\mathbf{L}_{\text {tabel }}$ & $\begin{array}{c}\text { Berdis } \\
\text { tribusi } \\
\text { Norm } \\
\text { Kesimpulan }\end{array}$ \\
\hline
\end{tabular}

\section{Uji homogenitas Data}

Tarif signifikasi L hitung sebesar 0, 1947 dan L tabel sebanyak 0,234 atau lebih dari 0,05, maka dapat dinyatakan bahwa data tersebut berdistribusi normal. Sedangkan kelompok 
control mempunyai tarif signifikasi L hitung 0,1899 dan L tabel 0,234 atau lebih besar dari 0,05 , maka dapat dinyatakan bahwa data tersebut berdistribusi normal. Dari hasil kelompok eksperimen dan control disimpulkan bahwa data yang diperoleh berdistribusi normal.

\section{Uji Hipotesis}

Pengujian $t$ hitung digunakan untuk mengetahui kualitas antara tiap-tiap variabel bebas $(\mathrm{X})$ terdapat pengaruh atau tidak terhadap variabel terikat $(\mathrm{Y})$.

Berdasarkan hasil output yang dilakukan oleh peneliti:

a. Variabel X1 ( Eksperimen) t hitung 4,156, dengan demikian $t$ hitung $>t$ tabel $(4,156>$ 2,064 ) yang secara statistik, variabel X1 (eksperimen) mempengaruhi variabel $\mathrm{Y}$ (Hasil Belajar) atau Ho ditolak dan $\mathrm{Ha}$ diterima.

b. Variabel X2 ( Kontrol ) t hitung 4,156, dengan demikian $\mathrm{t}$ hitung $>\mathrm{t}$ tabel $(4,156>$ 2,064 ) yang secara statistik, variabel X2 ( kontrol ) mempengaruhi variabel Y (Hasil Belajar ) atau Ho ditolak dan Ha diterima.

\section{PENUTUP}

Kesimpulan

Melihat manfaat dan kelebihan dari model pembelajaran learning contract tersebut yang begitu besar terhadap peningkatan dan kemampuan peserta didik, hal itu pun dipertegas oleh penelitian tentang pengaruh model pembelajaran learning contract terhadap peningkatan hasil belajar teknik pengelasan siswa kelas X Jurusan TKR SMK Negeri 1 Kakas.

Dengan adanya model pembelajaran learning contract dapat membuat siswa lebih aktif dan relatif yang akan menjadikan siswa lebih mandiri serta paham pada mata pelajaran yang akan dipelajari dikelas. Sehingga dapat disimpulkan bahwa pengguanaan model pembelajaran Learning Contract berpengaruh terhadap hasil belajar teknik pengelasan atau memberikan pengaruh positif kepada siswa.

Saran

Berdasarkan hasil penelitian ini peneliti berharap model ini bisa diterapkan oleh guru guna untuk meningkatkan hasil belajar siswa, bagi siswa agar lebih memperhatikan guru dalam proses pembelajaran berlangsung. Dan bagi peneliti selanjutnya, diharapkan bisa menjadi bahan kajian berikutnya dalam penelitian yang serupa.

\section{DAFTAR PUSTAKA}

Agus Suprijono. 2013. Cooperative Learning. Pustaka Pelajar. Yogyakarta.

Hasbullah. 2011. Dasar-Dasar Ilmu Pendidikan. Jakarta: PT Raja Grafindo Persada.

Hisyam Zaini dkk. 2008. Strategi Pembelajaran Aktif di Perguruan Tinggi: Centre for teaching staff Defelopment (CTsn).

http://journal.student.uny.ac.id. (diakses tanggal 11 januari pukul 22.00 WIB ).

Kadek Sukiyasa \& Sukoco. 2013. Pengaruh Animasi Terhadap Hasil Belajar dan Motivasi Belajar Siswa Materi Sistem Kelistrikan Otomotif. Jurnal Pendidikan Vokasi, Vol. 3, Nomor 1.

Melvin L Silberman. 2013. Active Learning 101 Cara belajar siswa aktif, ( Bandung: Nuansa.

Muslihin. 2013. Memahami Hal Penting dan Manfaat Kontrak Belajar. https://www. lihin. net. ( diakses 24 Oktober ). 
Sugihartono, dkk. 2012. Psikologi Pendidikan.

Yogyakarta: UNY Press.

Sugiyono, 2011. Metode Penelitian Pendidikan

Pendekatan Kuantitatif, Kualitatif, dan $R$ $\& D$. Alfabeta. Bandung.

Riduwan \& Sunarto, 2011. Pengantar Statistika Untuk Penelitian Pendidikan, Sosial, Ekonomi, Komunikasi, dan Bisnis. Lengkap Dengan Aplikasi SPSS 14. Alfabeta. Bandung.

Sudjana, 1986. Metode Statistik Edisi IV. Tarsito, Bandung 